المجلة الدولية للدراسات التربوية والنفسية

بحث رقم 19

المجلد التاسع، العدد الثاني، 689:677

نيسان (2021)

\title{
أثثر استخدام منحى الصور المتحركة الناطقة باللغة العربية الفصحى في تنمية مهارة الاستماع لدى تلاميذ الصف الثاني الأساسي في لواء وادي السير/ محافظة العاصمة
}

فواز حسن شحاده

أستاذ مشارك- جامعة الشرق الأوسط - الأردن
سناء أحمد العجرمي مساعدة مديرة في التعليم الخاص alajramisana@gmail.com 


\title{
أثر استخدام منحى الصور المتحركة الناطقة باللغة العربية الفصدى في تنمية مهارة الاستماع لدى تلاميذ الصف الثاني الأسـاسي في لواء وادي السير/ محافظة العاصيمة
}

\author{
سناء أحمد العجرمي \\ مساعدة مديرة في التعليم الخاص \\ alajramisana@gmail.com
}

فوازحسن شحاده

أستاذ مشارك- جامعة الشرق الأوسط- الأردن

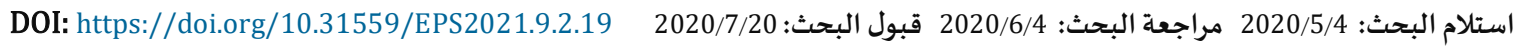

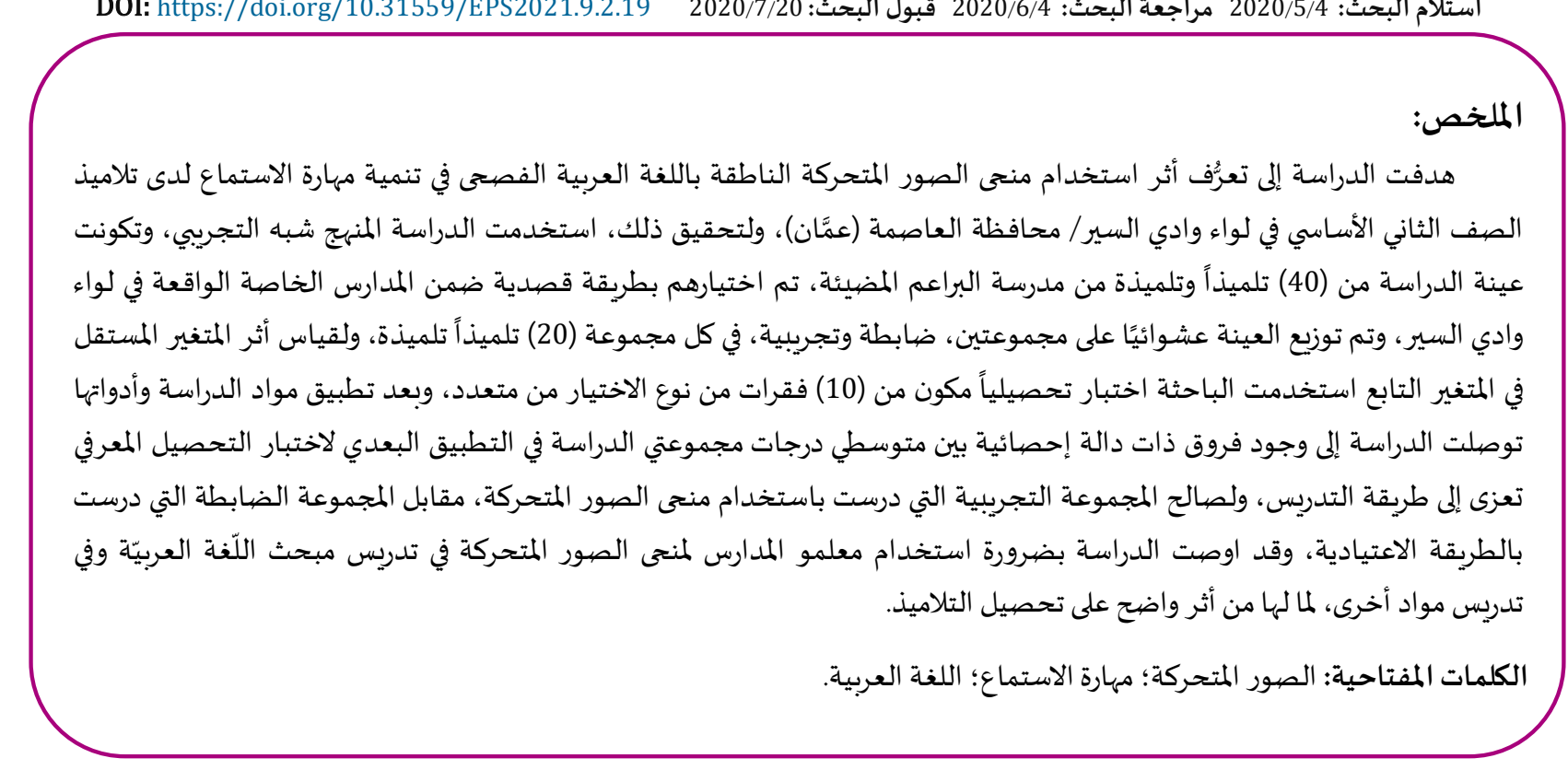

المقدمة:

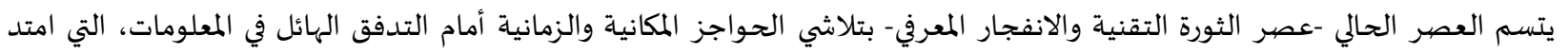

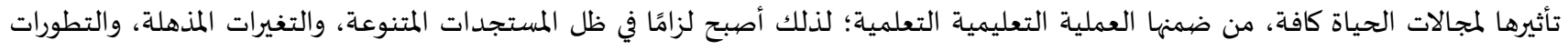

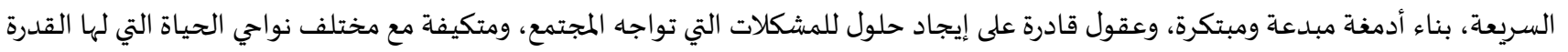

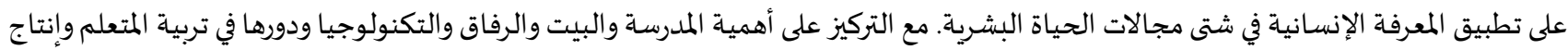

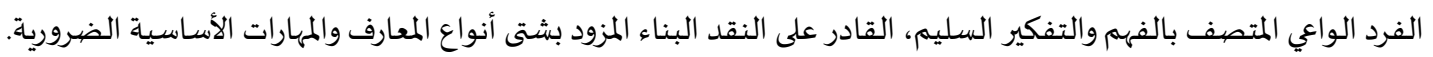

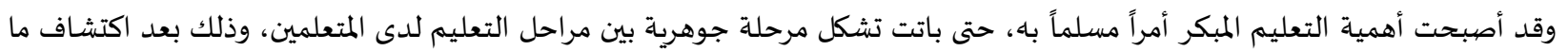

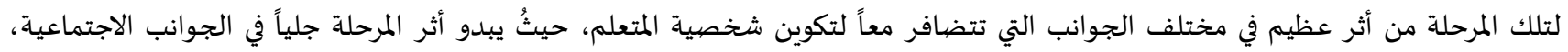

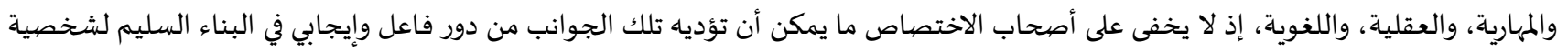
المتعلم، واستمرار نموه بالشكل الصحيح. ولعل الجانب اللغوي من أفضل تلك الجوانب من حيث أثره المباشر على الشخصية، الثانية، فاللغة هي وسيلة 
الاتصال الرئيسة بين الأفراد والجماعات، وعلى الفرد أن يمتلك المهارات اللغوية منذ سن مبكر، إذ ثبت في مجال التعليم أن تقدّم المتعلم في المواقف

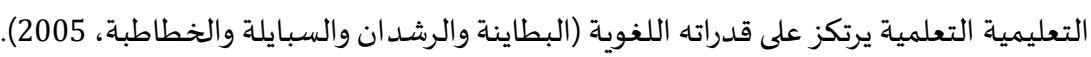
في السنوات الماضية بدأ التفكير في إدخال وتوظيف التكنولوجيا الحديثة في التعليم؛ الأمر الذي أدى إلى ظهور أشكال جديدة وتدئه ومتنوعة وأساليب

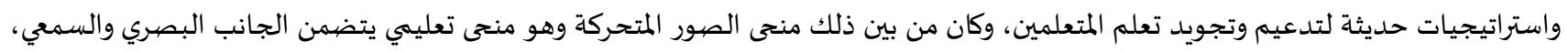

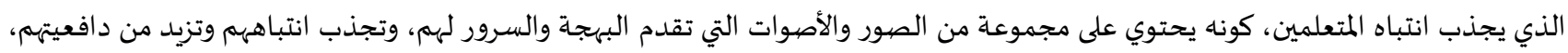

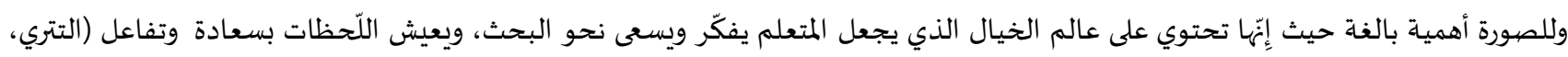

.(2016

وللّغة العربيّة مكانة خاصيّة وفريدة، فهي لغة القرآن، ولسان البيان، فمن الواجب الاعتزاز باللّغة العربيّة والاهتمام بتعليمها، فهي ليست مبحث

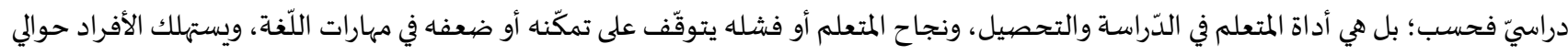

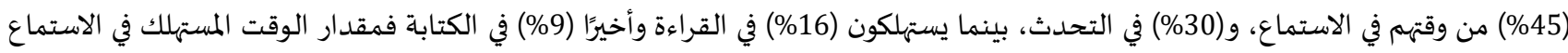

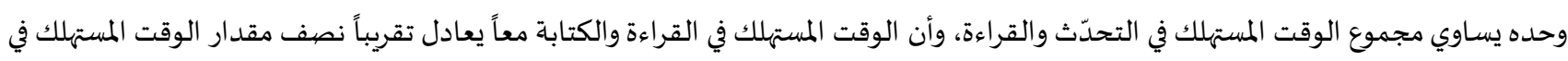

الاستماع وحددة (بوزان، 2002).

وفي ضوء ما تقدّم ارتأت الباحثة إجراء هذه الدراسة للتعرّف على أثر استخدام منحى الصور المتحركة الناطقة باللّفة العربيّة الفصدحى في تنمية

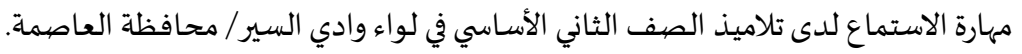

مشكلة الدراسـة:

ومن خلال خبرة الباحثة وعملها في المجال التربوي وإطلاعها على نتائج اختبارات وزارة التربية والتعليم لمبحث اللّغة العربيّة للعام (2018/2017)

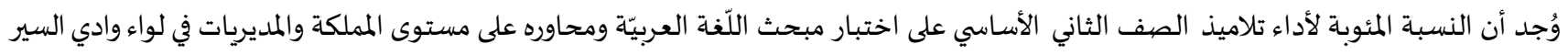

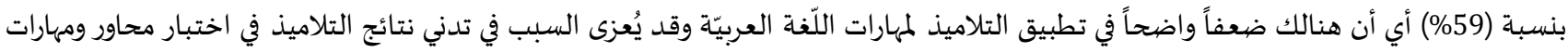

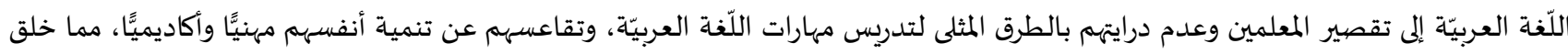

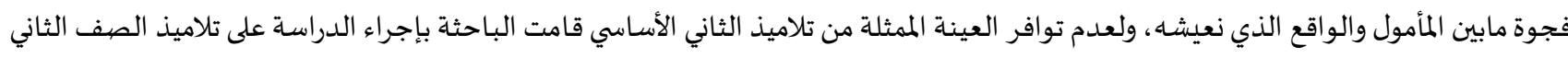

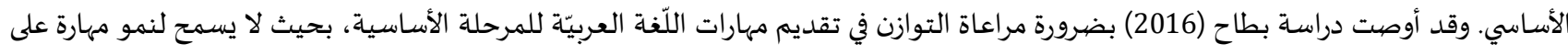

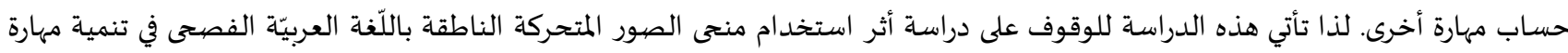

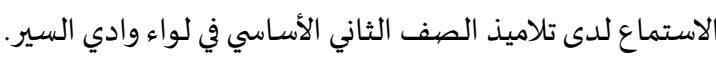

أسئلة الدراسـة: (1) تتمثل أسئلة الدراسة بالسؤال التالي "ما أثر استخدام منحى الصور المتحركة الناطقة باللّغة العربيّة الفصحى في تنمية مهارة الاستماع لدى تلاميذ

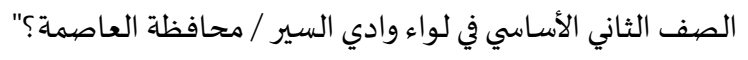

فرض الدراسـة:

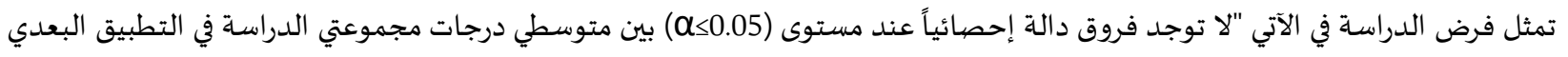
لاختبار التحصيل المعرفي تعزى إلى طريقة التدريس (منحى الصور المتحركة / الطريقة الإعتيادية)". أهدف الدراسة: تهدف الدراسـة إلى تقصّي أثر استخدام منحى الصيور المتحركة الناطقة باللّفة العربيّة الفصسى في تنمية مهارة الاستماع لدى تلاميذ الصف الثاني الأسـاسي في لواء وادي السير / محافظة العاصهمة. أهمية الدراسـة: تتمثل أهمية الدراسـة في الآتي: 1. يؤمّل أن تفيد الدراسة في تشكيل مهارات عليا لدى التلاميذ في الاستماع لتُسهم في الحفاظ على لغة القرآن الكريم واستدامتها في ظل متفيّرات 2. تساعد معلمي الصفوف الأولى في بناء شخصية المتعلم من خلال إثراء المخزون اللغوي لديه. 
3. قد تفيد في لفت نظر إدارة المناهج في وزارة التربية والتعليم والمشرفين التربويين وذلك عند وضع الخطط والبرامج المساعدة لرفع مستوى المتعلمين

في مهارة الاستماع.

$$
\text { تمثل حدود الدراسـة: }
$$

1. الحد الموضوعي: اقتصرت الدراسـة على الدرس الثاني عشر، والثالث عشر، والرابع عشر، من مبحث اللّفة العربية للصف الثاني الأساسي (مهارة

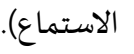

2. الحد البشري: تلاميذ الصف الثاني الأسـاسي في مدرسة البراعم المضيئة.

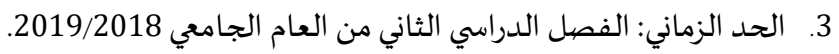

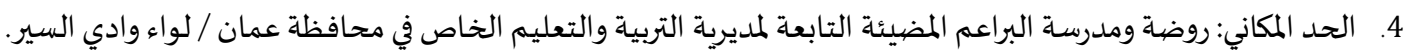

مصبطلحات الدراسـة:

تضمّنت الدراساة الحالية عدد من المصطلحات التي تم تعريفها مفاهيمياً وإجرائياً على النحو الآتي:

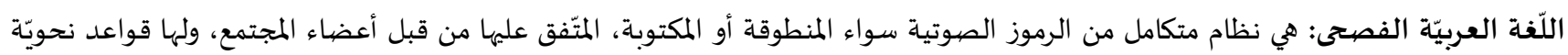

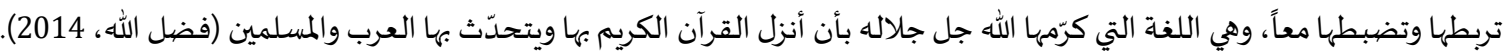

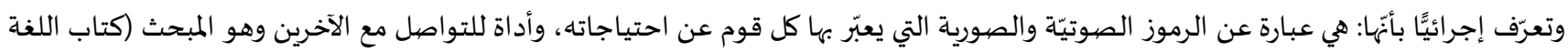

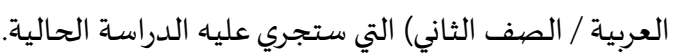

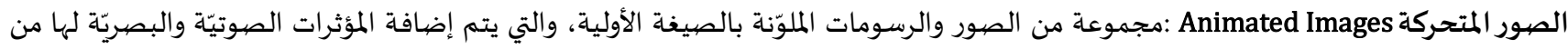

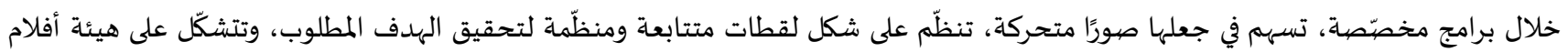

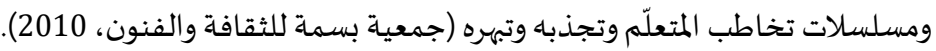

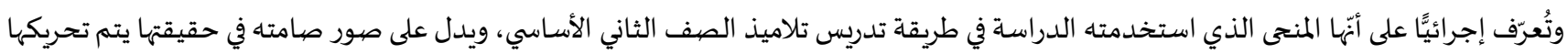

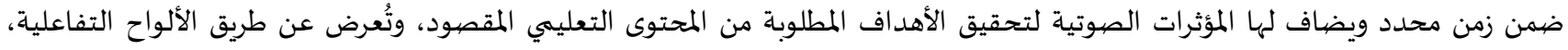
الفيديو، التلفاز واليوتيوب، كما هو الحال في أفلام الكرتون المتحركة.

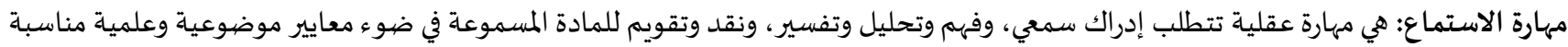
(مدكور، 2010) وتُعرّف إجرائيًا بأها: هي مهارة تحتوي على بعض المهارات الفرعية التي تستهدف إدراك الرموز الصيوتيّة المنطوقة من خلال التمييز السمعي والتصنيف

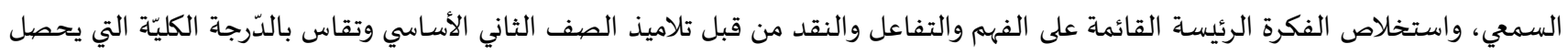

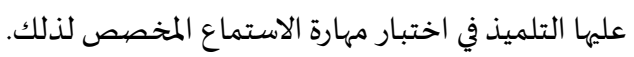

\section{الإطار النظري والدراسات السابقة:}

أولاً: الإطار النظري:

يتناول الأطار النظري للدراسـة، مهارة الاستماع من حيث أهميتها وتعريفها، وأنواعها وشروط نجاحها، كما يتناول الصهور المتحركة، وذلك على

$$
\begin{aligned}
& \text { النحو التالي: } \\
& \text { 1. مهارة الاستماع: } \\
& \text { • أهمية مهارة الاستماع: }
\end{aligned}
$$

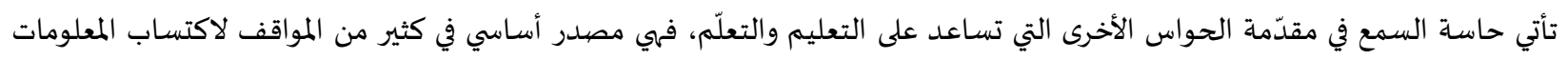

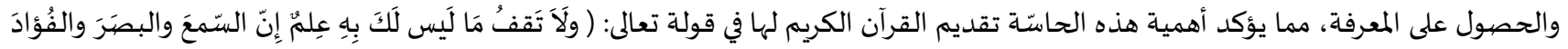

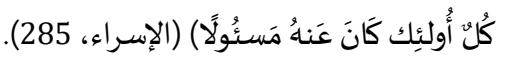

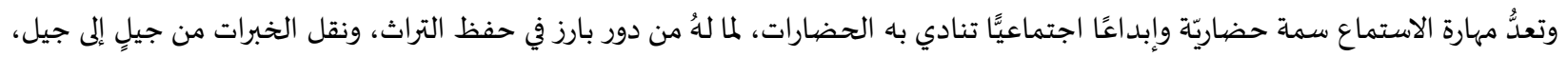

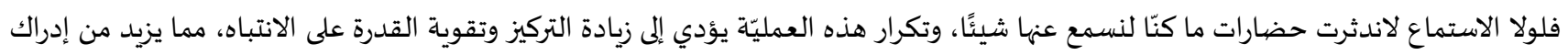

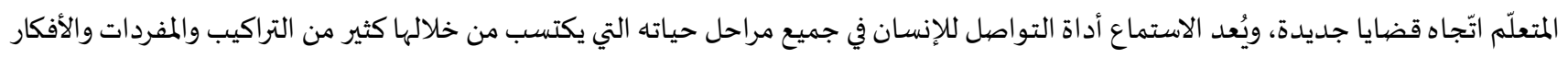

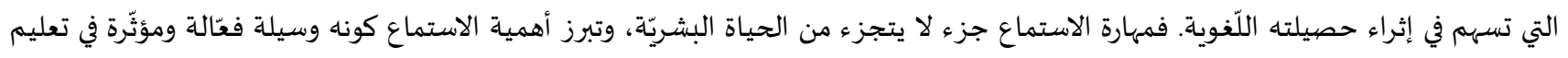


الإنسان بصفة عامة والأطفال بصفة خاصهة، ولما لها دور في عملية الاستيعاب والتحصيل لدى الأطفال، حيث أن الأطفال بأشدّ الحاجة إلى تنمية هذه

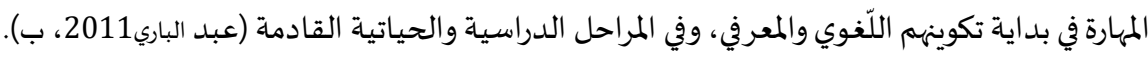

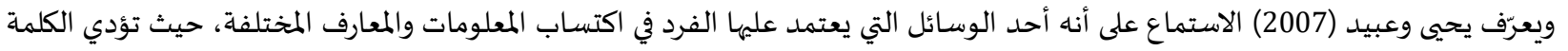

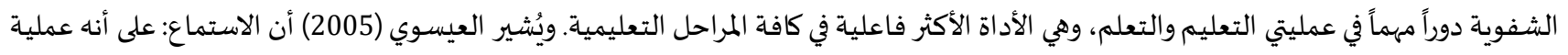

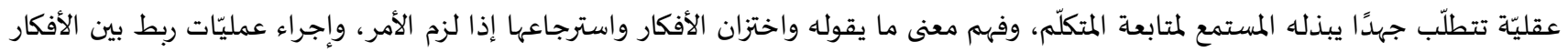

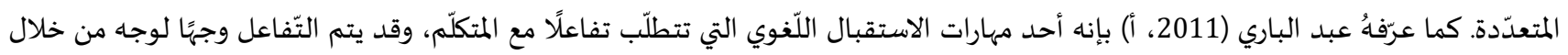

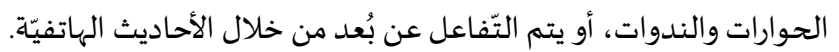

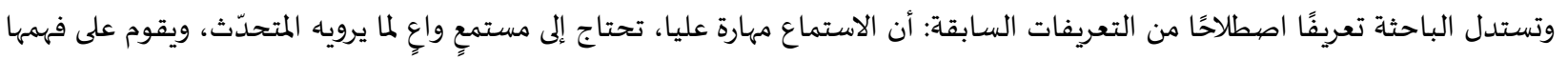

وتحليلها ونقدها، لتحسين مهاراته التواصلية. • ب أنواع الاستماع: كشفت الأبحاث عن عدة أنواع للاستماع وليس نوعاً واحداً، تستخدم بشكل متداخل في الحياة اليوميّة أو تختلف بأختلاف المواقف التعليمية،

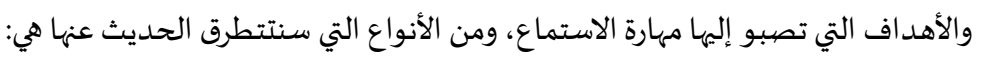
أ- الاستماع التذكري: ويكون الغرض من الاستماع استرجاع ما تم سماعه وتذكره وتتابع الأفكار والأحداث، أو استعادة أجزاء مهمة منها (عطية،

(2008 ب- الاستماع الاستمتاعي: هو الذي ينصبُّ فيه الذهن على المتعة واستغلال الفراغ، والترويح عن النفس، ويرتبط كثيرًا بميول الفرد، هذا النوع

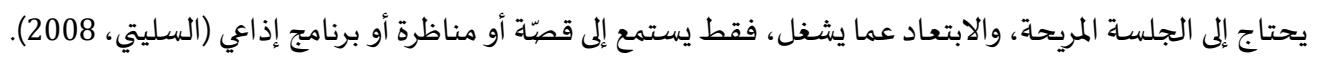

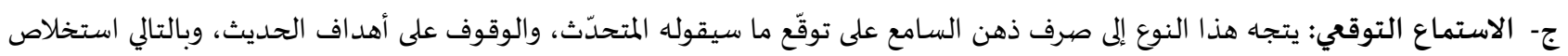

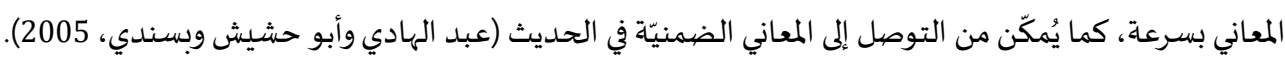

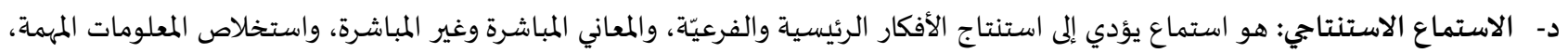
والنتائج الصحيحة (عون، 2012). هـ- الاستماع التحصيلي: هو نوع من الاستماع الذي يرتبط بالمدرسة وقاعات الدرس والمحاضرات المات والندوات والمناقشات، والهدف منها تحصيل

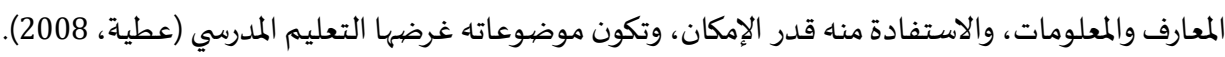

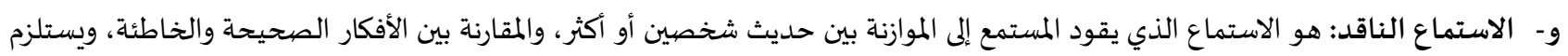

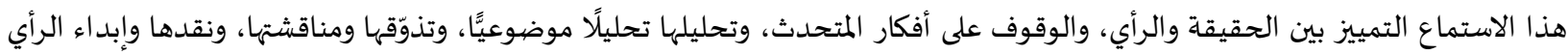

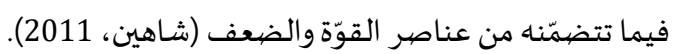
وخلاصية القول فإن الأنواع السابقة من الاستماع ترتبط بمواقف معيّنة. يجمع الفرد بين الفين أكثر من نوع في الموقف الواحد مثلاً: إذا كان في ندوة قد يجمع بين الاستماع الاستمتاعي والتحصيلي والتذكري والاستنتاجي. شروط نجاح مهارة الاستماع: حتى تكون مهارة الاستماع جيّدة وتؤتى ثمارها، يجب أن تخضع لعدئ لعدّة شروط منها توافر البيئة الفيزيقيّة المناسبة التي تخلو من مسببات الإزعاج

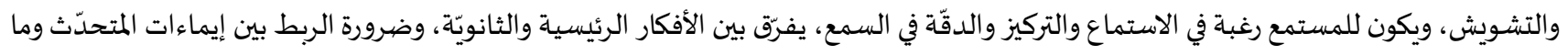

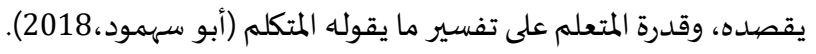
2. 2 شهد العالم خلال العقدين الماضيين ما لم تشهده الأمم السابقة من تحدّيات وتطوّرات تقنيّة، والتي جعلت العالم قرية صغيرة (القرية

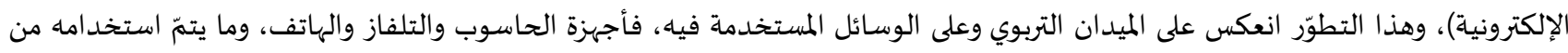

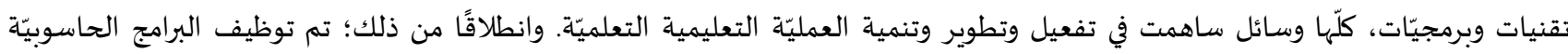

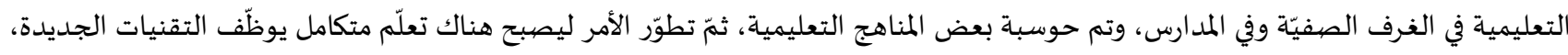

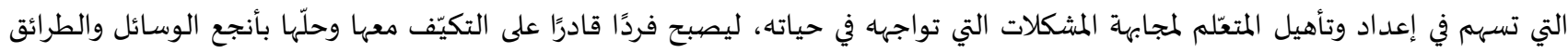

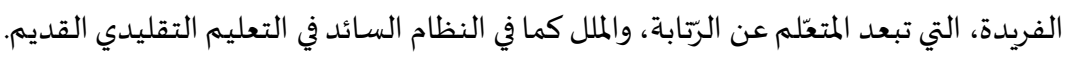

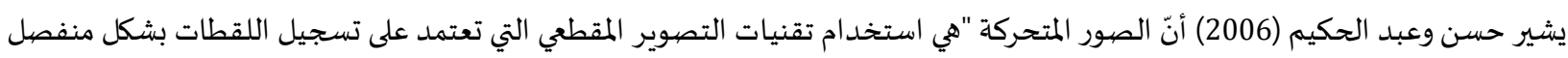

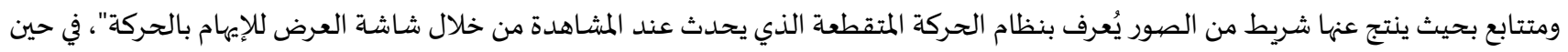
يرى دابل ( Dabell, 2008:43) أنّ الصور المتحركة هي "رسوم رمزيّة أو خلفيات بصريّة تستخدم النسق أو التصميم الكرتوني لتقديم المحادثات داخل

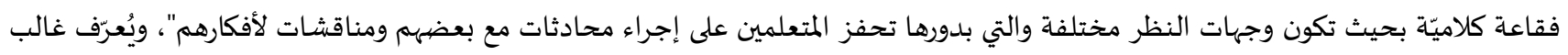


(Birisci, Metin, الصور المتحركة: عبارة عن لقطات متتابعة ومتلاحقة تعتمد على الحركة والسرعة المنظمة عند عرضها، بينما يرى بريسي)

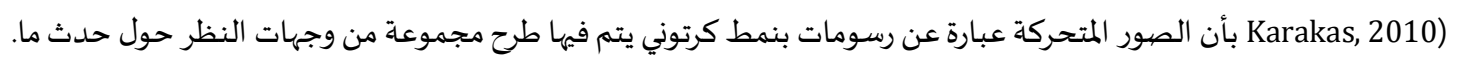

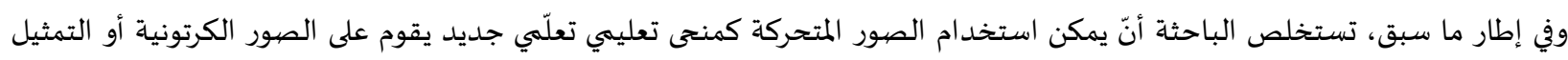

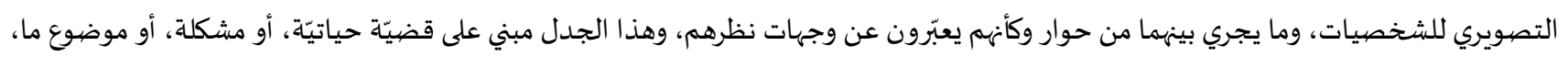

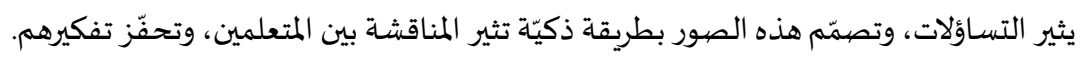

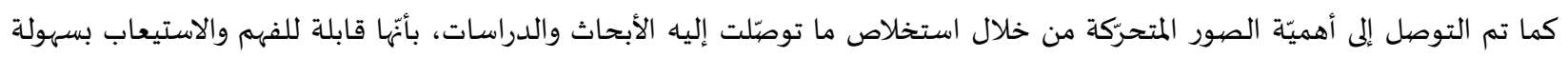
وسرعاة، مما يجعلها جذّابة ومشوّقة للمتعلمين، وبالتّالي يمكن توظيفها في العمليّة التعليمية التعلميّة. كما وتسههم الصهور المتحرِّكة في النّمو الأخلاقي

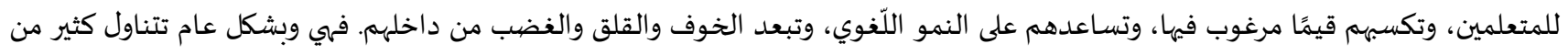

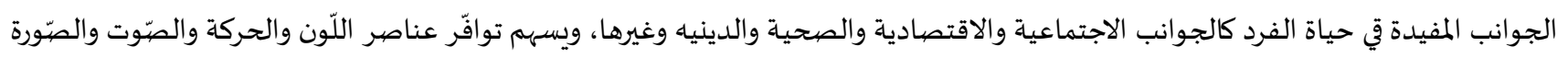

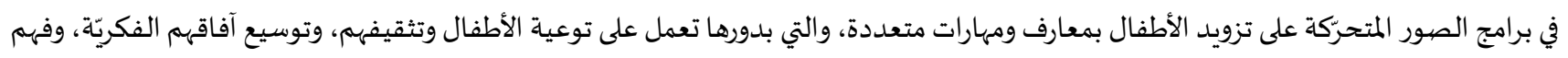
البيئة المحيطة بهم (شديفات، 2006).

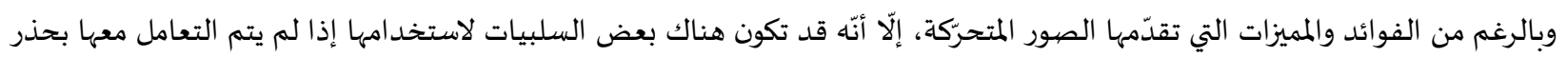

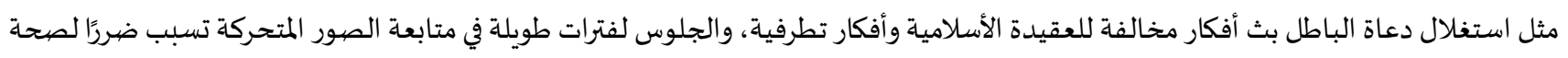

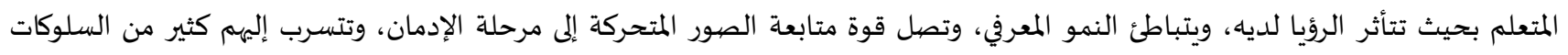

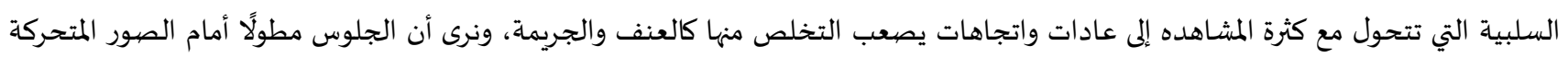

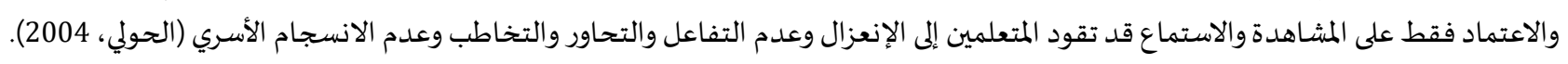

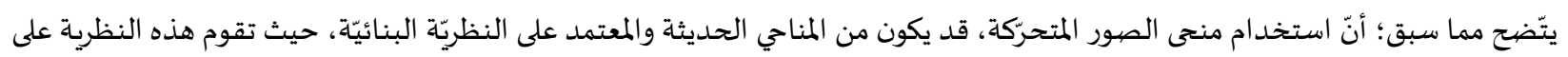

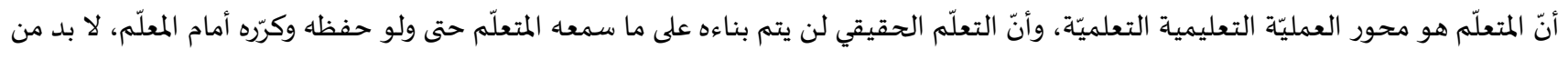

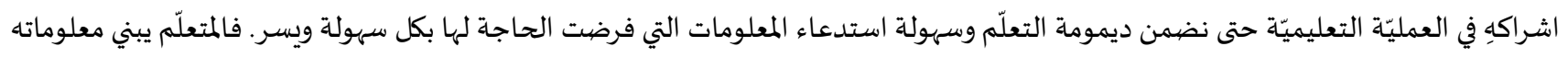

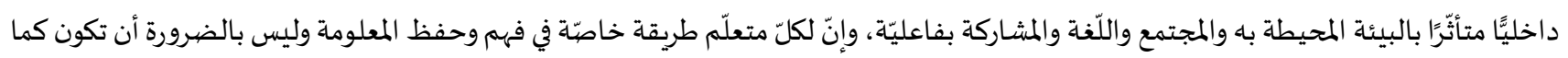

$$
\text { يريد المعلّم. }
$$

ثانياً: الدراسات السابقة: تم الاطلاع على الدراسات السـابقة ذات الصلة بالموضيوع، وتم عرضها حسب التسلسل الزمني من الأقدم إلى الأحدث، وكان من أهم تلك الدراسات ما يلي: دراسة قربان (2012) التي هدفت إلى الكشف عن فاعليّة قصص الرسوم المتحركة في تنمية بعض المفاهيم العلمية والقيم الاجتماعية لأطفال

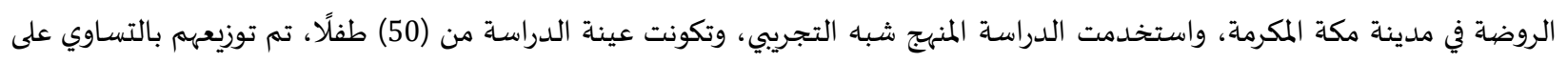

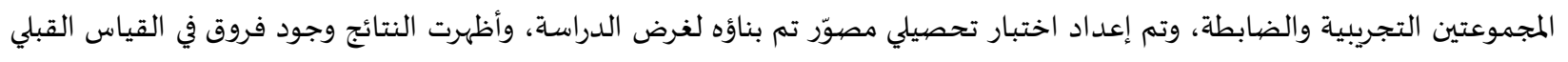

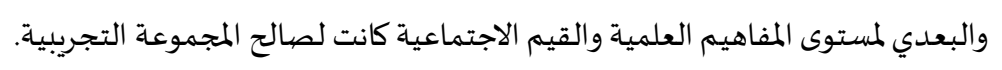
وسعى بينتر ورادوساف (Pinter\& Radosav,2012) إلى دراسة لتحليل تأثير استخدام الصور المتحركة التفاعلية في التدريس في صربيا، واستخدمت الدراسة المنهج شباء التجريبي، وتكونت عينة الدراسة من (97) طالبًا وطالبة، تم تقسيمهم على مجموعتين تجريبية والأخرى ضيابطة،

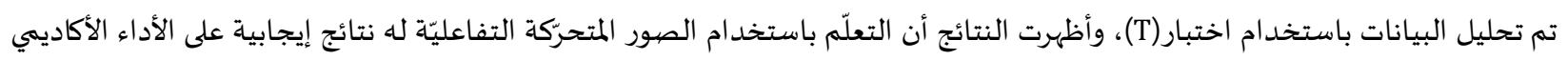
لغالبية الطلبة. واستقصت دراسة وافي (Wafi, 2013) فعالية استخدام برنامج الصور المتحركة في تعلّم مفردات اللّخة الإنجليزية لدى طالبات الصف الخامس في فلسطين، اعتمدت الدراسة المنهج شبه التجريبي، وتكونت عينة الدراسة من (64) طالبة ووزعت العينة على مجموعتين بواقع (32) (32) طالبة

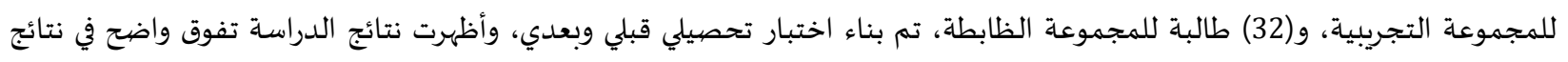
الاختبار التحصيلي لصالح المجموعة التجريبية التي طبق عليها برنامج الصور المتحركة. وهدفت دراسة الزق (2014) التعرّف إلى أثر توظيف الصور المتحركة في تنمية مهارات التعبير اللّغوي لدى طلاب الصف الصفي الرابع الأساسي في غزة

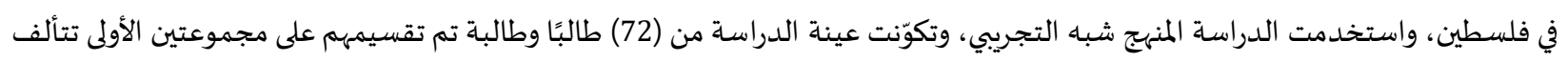

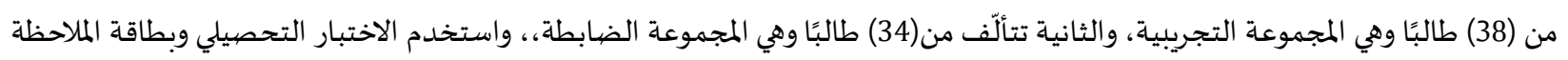
كأدوات للقياس، وأظهرت النتائج وجود فروق واضئحة المجوعة في مستويات التلاميذ الذين درسوا بالطريقة الاعتيادية مقارنة بنتائج المتعلمين الذين درسوا باستخدام الصور المتحركة لصالح المجموعة التجريبية. 
وأجرى وارت وموه (Warat\& Moh, 2014) دراسة للتعرف إلى تأثير فيلم الصيور المتحركة في مهارات الاستماع لطلبة جامعة Smkn1 batulayar في ماتارام في اندونيسيا، حيث استخدمت الدراسة المنهج شباه التجريبي، وتكونت عينة الدراسـة من (64) طالبًا تم تقسيمهم على مجموعتئين الأولى

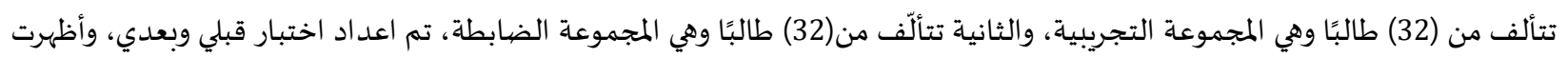

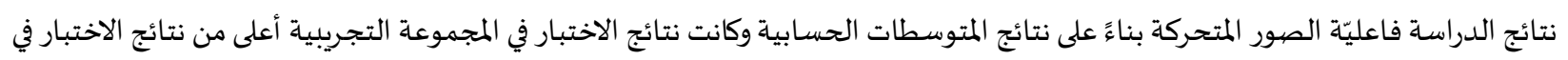
المجموعة الضيابطة.

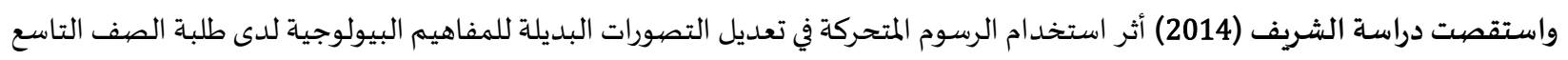

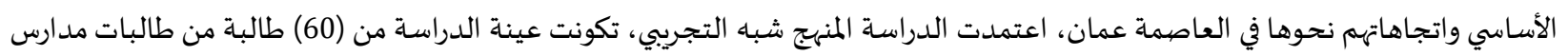

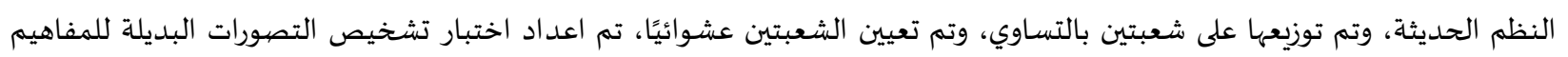

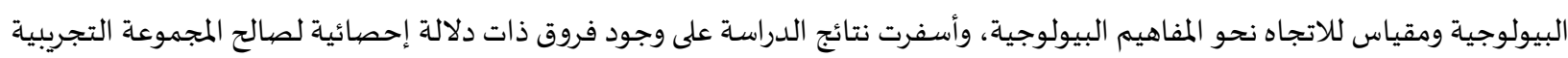
التي درست باستخدام الرسوم المتحركة في تعديل التصيورات البديلة للمفاهيم البيولوجية. كما أجرت أبو حوار (2017) دراسة سعت للكشف عن أثر توظيف استراتيجية الصور الكرتونية على تنمية المفاهيم ومهارات التعبير الكتابي

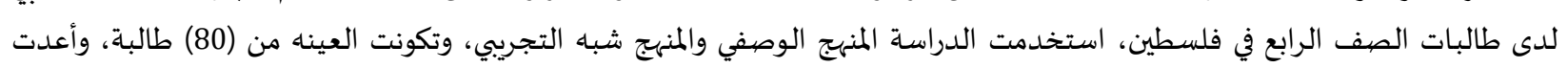

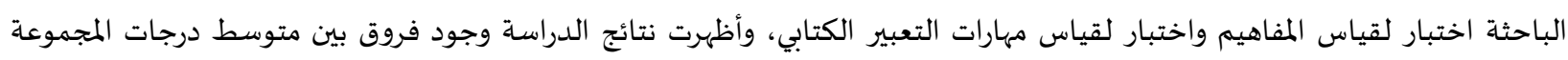

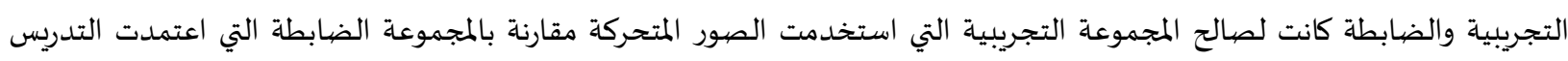

بالطريقة الاعتيادياة.

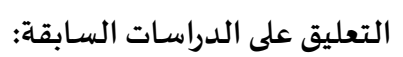

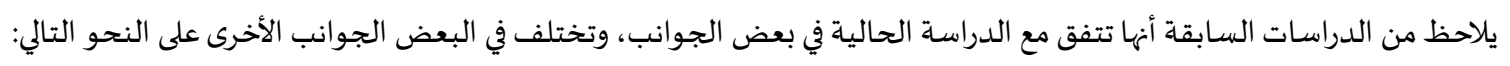

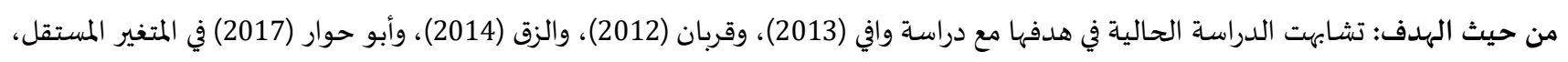

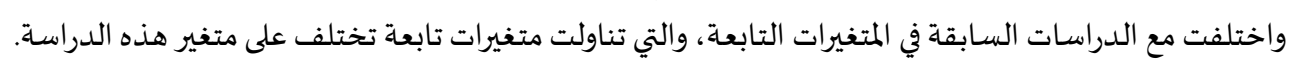

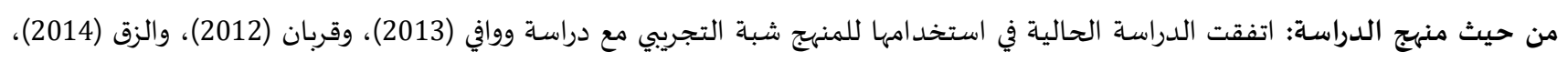

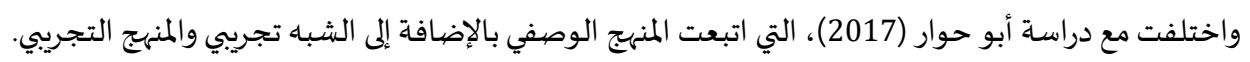

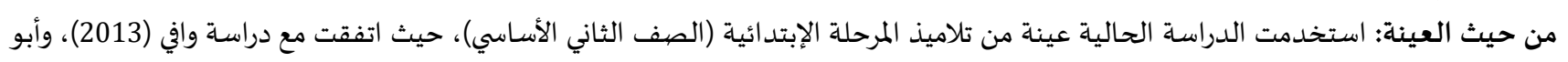

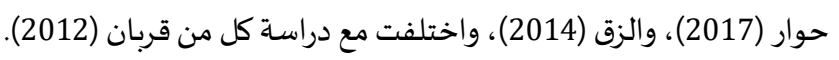

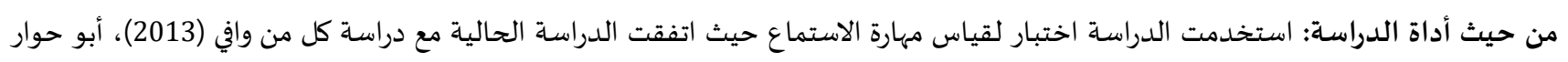
(2017)، الزق (2014)، واختلفت مع دراسة الشريف (2014)، بيتر ورادوساف (2012).

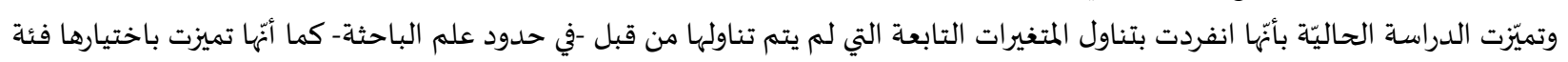

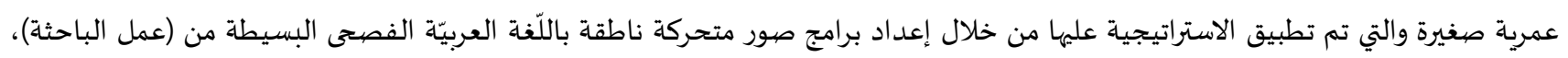

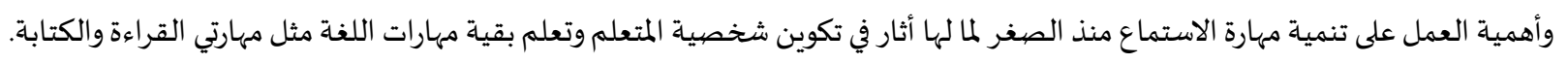

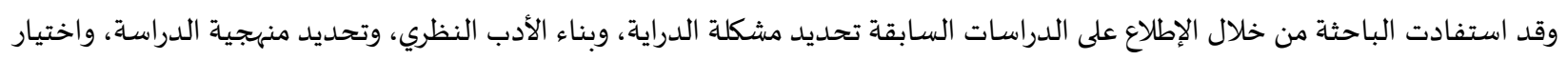

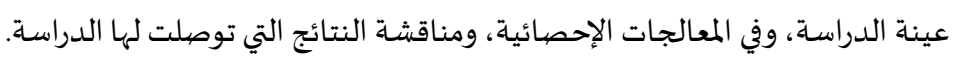

الطريقة والإجراءات: منهج الدراسة: استخدمت الدراسـة المنهج شبه التجريبي لمناسبته لأغراض الدراسـة.

مجتمع الدراسـة وعينتها: تكون مجتمع الدراسة من جميع تلاميذ الصف الثاني الأساسي في المدارس الخاصة في لواء وادي السير، تم اختيار مدرسة البراعم المضيئة في لواء

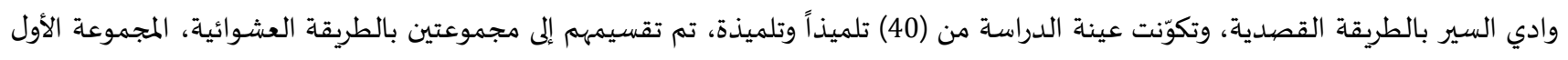
التجريبية وعددها (20) تلميذاً وتلميذة، تم تدريسهم باستخدام منحى الصور المتحركة، والمجموعة الثانية الضابطة وعدية المدردها (20) تلميذاً وتلميذة، تم تدريسهم بالطريقة الإعتيادية. 


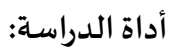

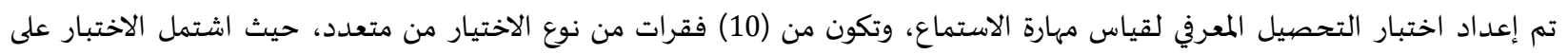
مستويات بلوم (تذكر، فهم، تطبيق، تحليل، تركيب، تقويم) وتم إعداد الاختبار بإتباع الخطوات التات الآتية:

تحديد النتاجات التعيلمية للدروس وتحليل محتواها.

بناء جدول المواصفات في ضوء النتاجات التعليمية. إعداد فقرات الاختبار في ضوء جدول المواصفات والنتاجات التبات التعليمية.

وضع تعليمات الاختبار ، والعلامة القصوى للاختبار (10) حيث وضيعت علامة واحدة لكل فقرة من فقرات الاختات الاختبار.

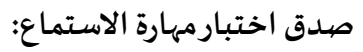

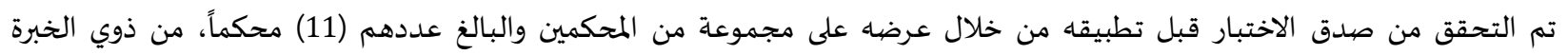

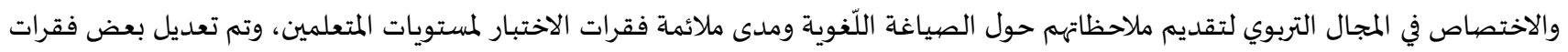

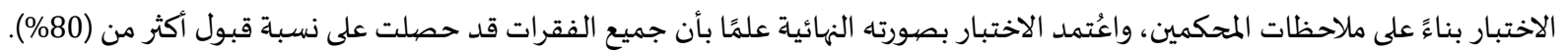

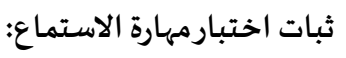

تم فحص ثبات الاختبار باستخدام طريقتين هما:

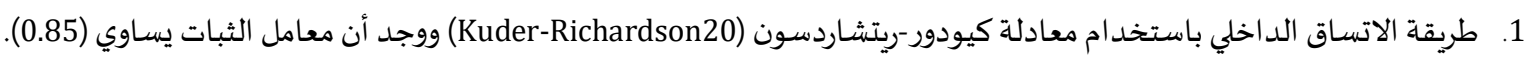

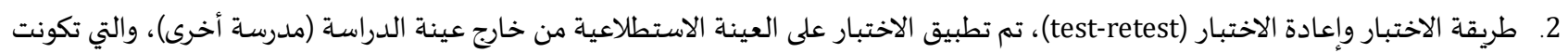

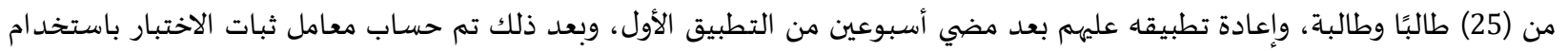

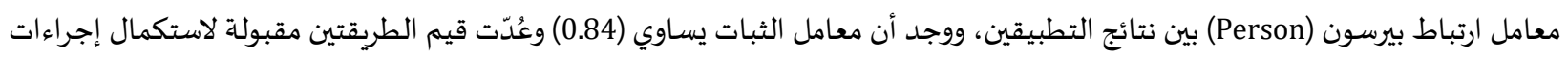

الدراسة.

معاملات الصعوبة والتميز لاختبار مهارة الاستماع:

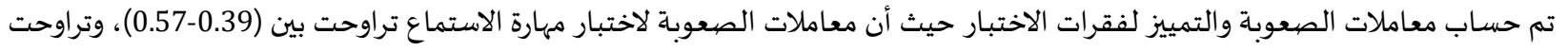

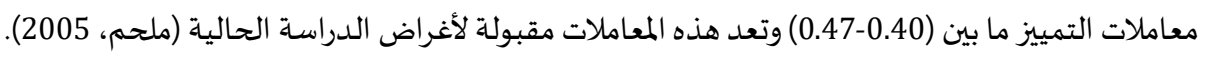

المواد التجريبية للدراسة:

استنادًا إلى الأدب التربوي حول الصيور المتحركة، فقد تم كتابة الخطط التدريسية للدروس التجريبية دروس الاستماع لمادة اللغة العربية للصفف

الثاني الأساسي، من خلال برمجية مايكروسفت بوربوينت Microsoft PowerPoint ، وقد تكونت الخطة من ثلاثة دروس على النحو التالي:

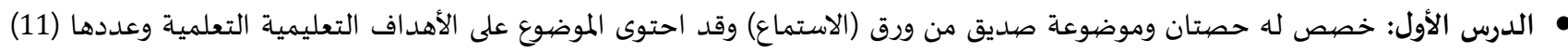

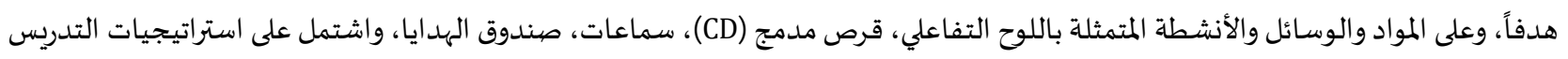

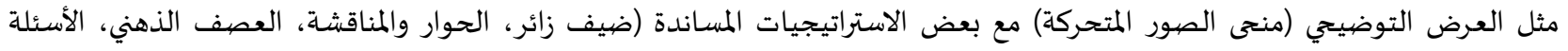

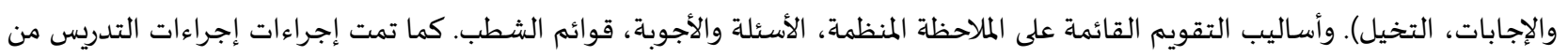

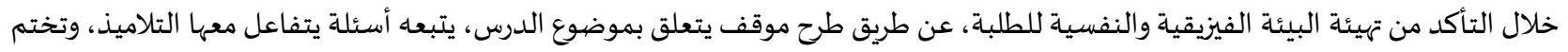

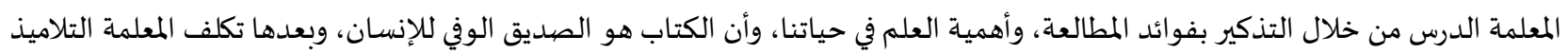

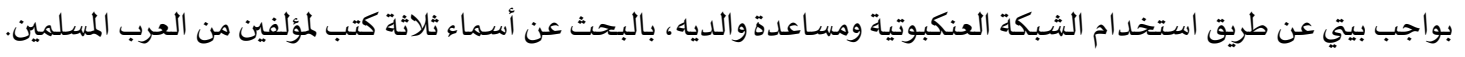

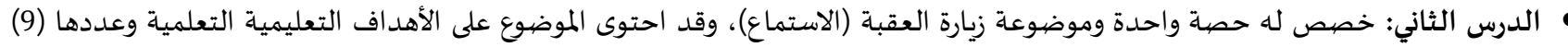

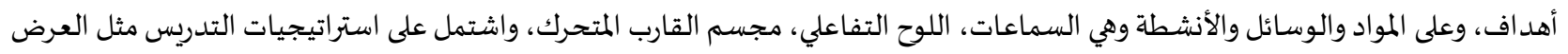

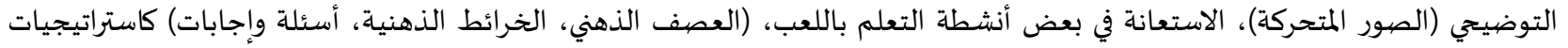

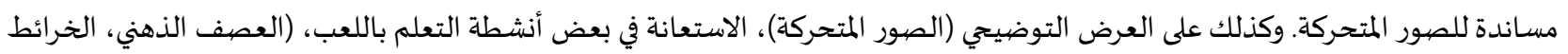

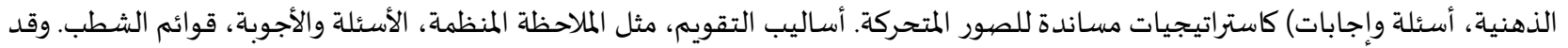

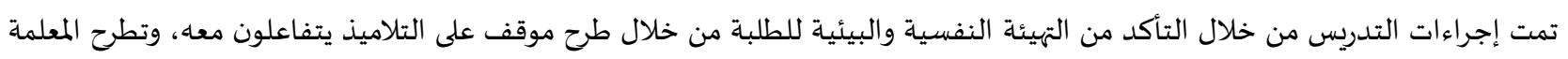

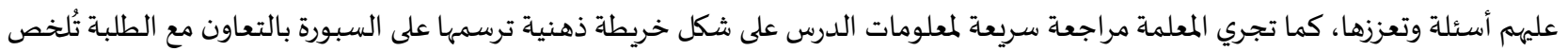

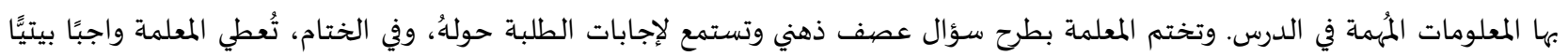
ليبحثوا في شبكة الإنترنت. 
الدرس الثالث: خصص له حصة واحدة وموضوعة النملة النشيطة (الاستماع)، وقد احتوى الموضوع على الأهداف التعليمية التعلمية وعددها

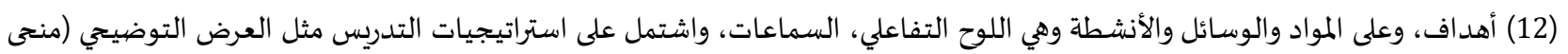

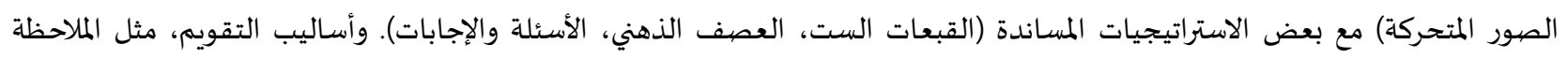

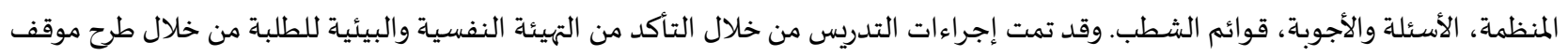

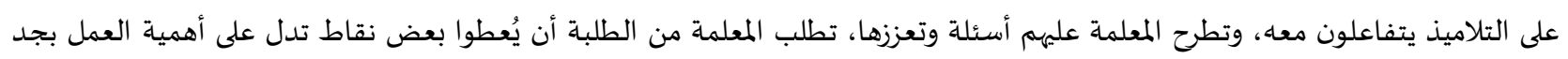

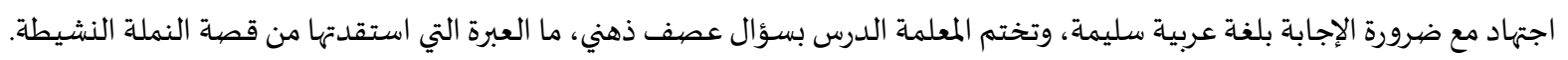

خطوات تطبيق الدراسة:

قامت الباحثة بالاعتماد على الخطوات الآتية في تطبيق الدراسـة:

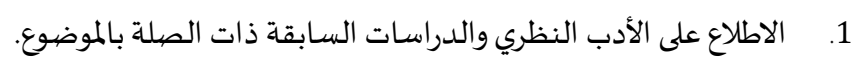

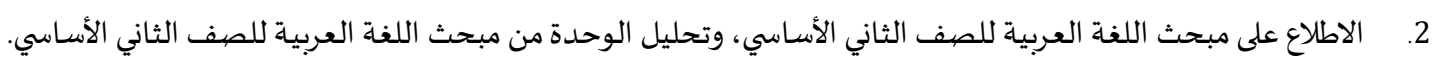

3. إعداد خطة الدروس باستخدام الصهور المتحركة.

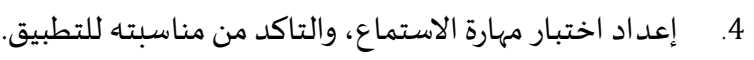

5.

6.

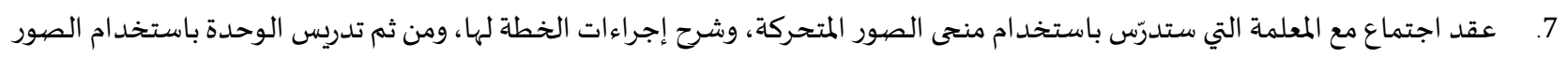

المتحركة للمجموعة التجريبية والمجموعة الضابطة بالطريقة الاعتيادية.

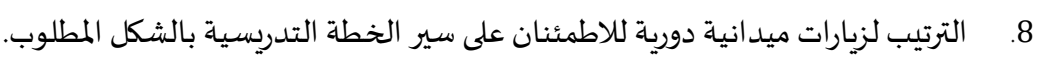

9 9.

10.

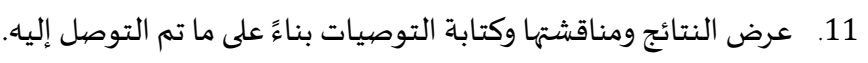

تكافؤ مجموعتي الدراسـة:

تم التأكد من تكافؤ مجموعتي الدراسة (الضابطة والتجريبية)، من خلال تطبيق اختبار التحصيل المعرفي الخاص بمهارة الاستماع قبلياً على المار

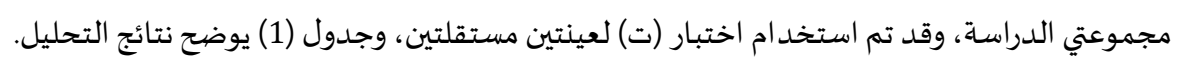

\begin{tabular}{|c|c|c|c|c|c|c|c|}
\hline الدلالة & قيمة & درجات & المعياري & المسسابي & العظهى & المجموعة & الأداة \\
\hline \multirow{2}{*}{0.000} & \multirow{2}{*}{0.489} & \multirow{2}{*}{1} & 1.67 & 5.55 & 10 & التجريبية & اختبار التحصيل \\
\hline & & & 1.50 & 4.85 & 10 & الضابطة & المعرفي \\
\hline
\end{tabular}

يلاحظ من جدول (1) عدم وجود فروق ذات دلالة إحصائية عند مستوى (م<0.05) بين متوسط درجات المجموعتين في الاختبار التحصيلي المعرفي، مما يشير إلى تكافؤ مجموعتي الدراسة قدولياً.

نتائج الدراسة ومناقشتها: النتائج المتعلقة بسؤال الدراسة والفرض الخاص به ونصيه "لا توجد فروق دالة إحصائيا عند مستوى (م>0.05) بين متوسطي درجات مجموعتي

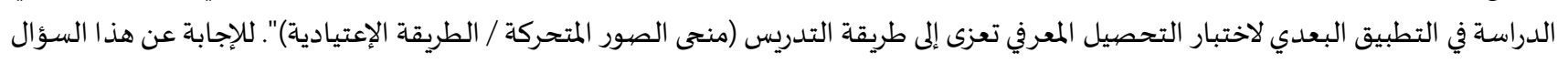

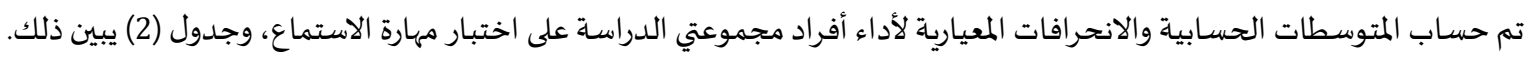


جدول (2): المتوسطات الحسابية والانحر افات المعيارية لأداء مجموعتي الدراسة على اختبارمهارة الاستماع القعاع البعائ

\begin{tabular}{|c|c|c|c|c|c|c|}
\hline \multicolumn{2}{|c|}{ البعدي } & \multicolumn{2}{|c|}{ القبلي } & \multirow[b]{2}{*}{ الدرجة العظهى } & \multirow[b]{2}{*}{ العدد } & \multirow[b]{2}{*}{ المجموعة } \\
\hline المعياري & المتوسط الحسابي & المعياري & الحستابي & & & \\
\hline 1.19 & 8.40 & 1.67 & 5.55 & 10 & 20 & التجريبية \\
\hline 0.60 & 6.60 & 1.50 & 4.85 & & 20 & الضابطة \\
\hline
\end{tabular}

يلاحظ من جدول (2) أن المتوسط الحسابي لأداء أفراد المجموعة التجريبية الذين درسوا باستخدام منحى الصهور المتحركة الناطقة باللغة

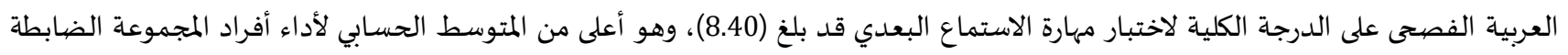

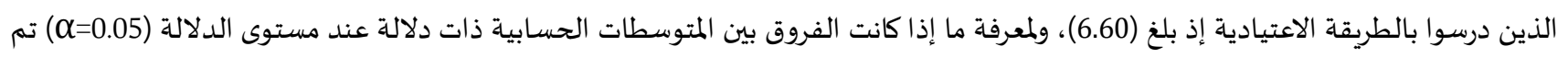

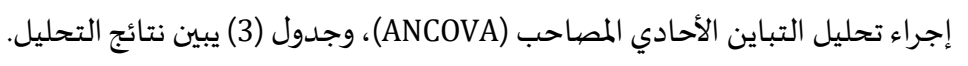

\begin{tabular}{|c|c|c|c|c|c|c|}
\hline (مربع ايتا) حجم الأثر & مستوى الدلالة & قلمحسمة ف & متوسط المربعات & درجات الحرية & مجموع المربعات & التباين \\
\hline - & - & - & 0.344 & 1 & 0.344 & الاختبار القبلي \\
\hline 0.489 & 0.000 & 35.372 & 31.792 & 1 & 31.792 & طريقة التدريس \\
\hline - & - & - & 0.899 & 37 & 33.256 & الخطأ \\
\hline - & - & - & - & 39 & 66.000 & الكلي المعدل \\
\hline
\end{tabular}

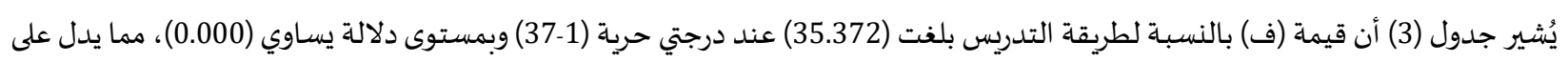

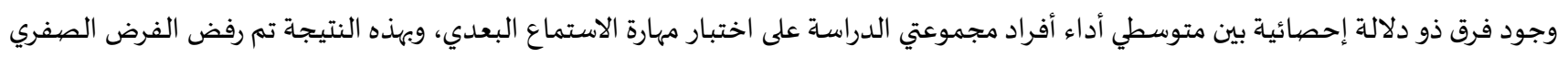

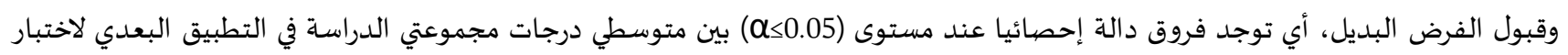

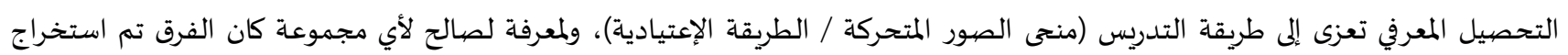
المتوسطات الحسابية المعدلة، والتي تظهر في الجدول لمعيد الآتي.

\begin{tabular}{|c|c|c|}
\hline الخطأ المعياري & الوسط الحسابي المعدل & المجموعة \\
\hline 0.21 & 8.39 & التجريبية \\
\hline 0.21 & 6.61 & الضابطة \\
\hline
\end{tabular}

يبين جدول (4) أن المتوسط الحسابي المعدل لدرجات أفراد المجموعة التجريبية الذين درسوا باستخدام منحى الصور المتحركة الناطقة باللغة

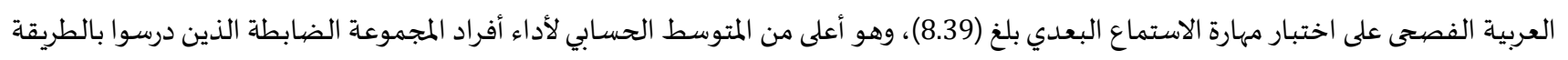

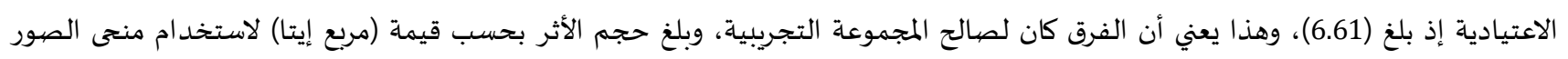

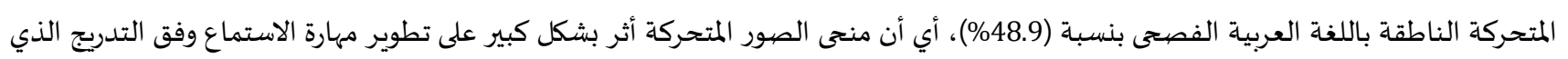

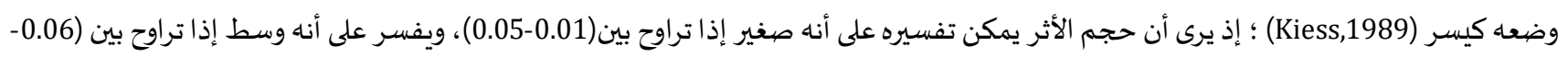
0.13)، بينما يفسر على انه كبير إذا بلغ (0.14) أو أكثر.

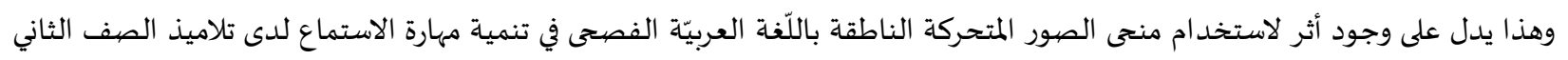

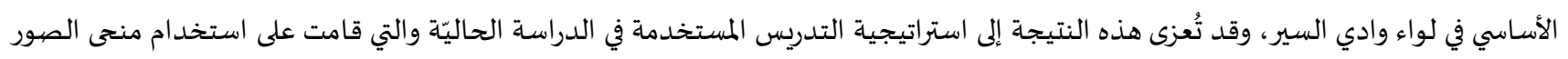

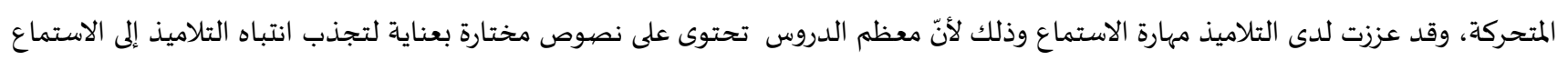

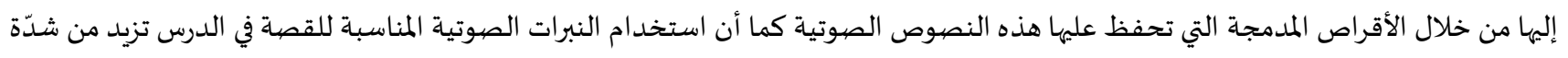

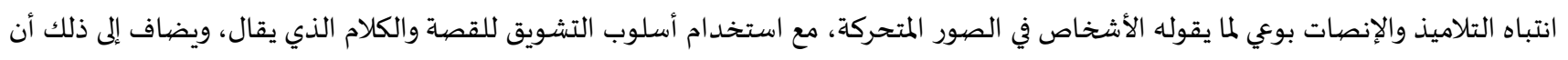
النص الصوتي في معظم الدروس يحتوي على لغز يتناسب مع مستوى التلاميذ وتقوم المعلمة بالطلب منهم حلّ اللّغز ولذلك كان التهام التلاميذ ينصيتون

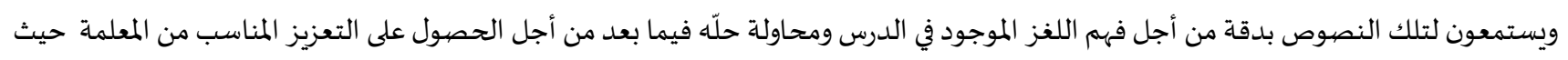




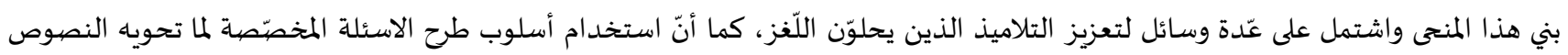

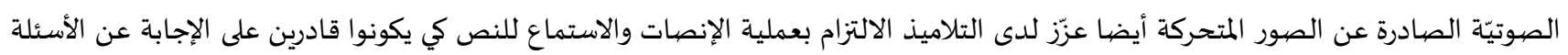

المرتبطة بما تقوله الشخصيات في الصيور المتحركة.

ويضاف إلى ذلك أن طبيعة الصهور المتحركة التي تستخدم التصميم الكرتوني لتقديم المحادثات داخل فقاعة كلامية بحية بحيث تكون وجهات النظر

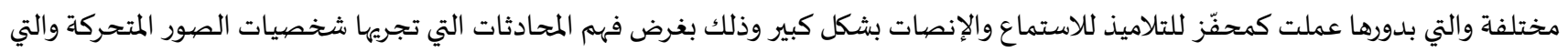

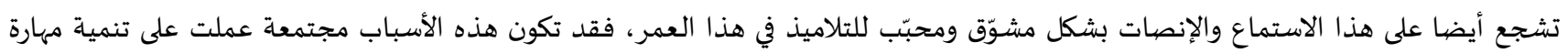

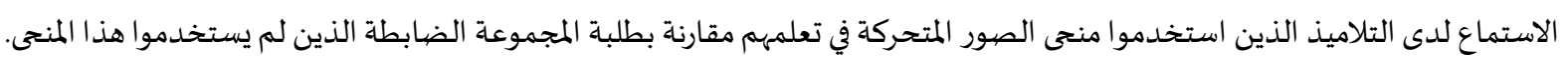

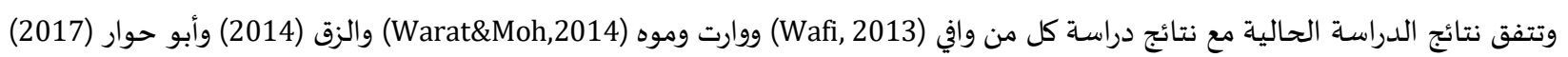
والتي أشـارت نتائجها إلى تحسن مستوى طلبة المجموعة التجربية في مهارات الاستماع والكتابة نتيجة استخدام الصور ولمت المتحركة. التوصيات:

في ضوء ما توصلت إلها الدراسة من نتائج، توصي الباحثة بما يلي:

ضرورة استخدام معلمو المدارس لمنحى الصور المتحركة في تدريس مبحث اللّغة العربيّة وفي تدريس مواد أخرى، لمالها من أثر واضح على تحصيل التلاميذ.

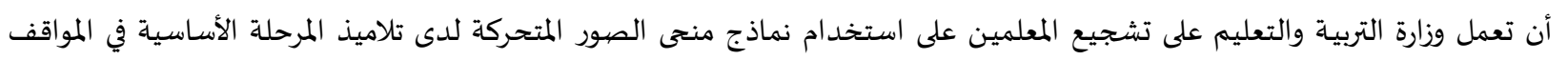

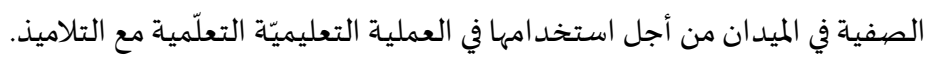

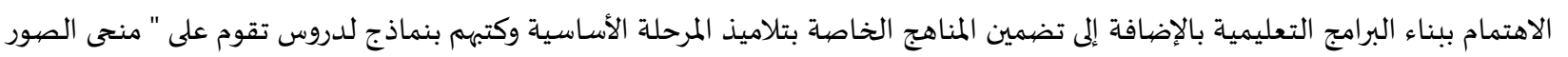
المتحركة " ليتفيد المعلمون في تدريسهم. عقد دورات تدريبية لمعلمي ومعلمات المرحلة الأساسية حول إعداد البرامج التعليمية القائمة على منحى الصهور المتحركة واستخدامها في العملية التعليمية التعلّمية لما لهما من أثر في زيادة تحصيل التمعلاميذ في مهارات المهات الاستماع والتحدث.

المقترحات:

في ضوء ما توصلت إليها الدراسة من نتائج، تقترح الباحثة ما يلي:

تشجيع الجامعات والباحثين على القيام بدراسـة متعلقة باستخدام منحى الصور المتحركة واستخداماتها في تنمية مهارات اللغة العربية. تشجيع الجامعات والباحثين على الاستمرار في القيام بالبحوث المتعلقة باستخدام منحى الصور المتحركة واستخداماتها في تنمية العمليات العقلية المختلفة لدى التلاميذ.

1. بطاح، عبد الحليم (2016). أثر توظيف مسرحة الدروس في تنمية مهارات التعبير الشفهي لدى تلاميذ الصفف الثالث الأساس بغزة. رسالة ماجستير غير منشورة، الجامعة الإسلامية: فلسطين. 2. البطاينة، أسامة والرشدان، مالك والسبايلة، عبيد والخطاطبة، عبد (2005). صعوبات التعلم النظرية والممارسة. عمان: دار المارينة المسيرة للنشر والتوزنع والطباعة.

3. بوزان، توني (2002). الاستخدام الأقصى لطاقات الدماغ العقلي. ط2. ترجمة (إلهام خوري). دمشق: دار الحصاد للطباعة والنشر والتوزيع.

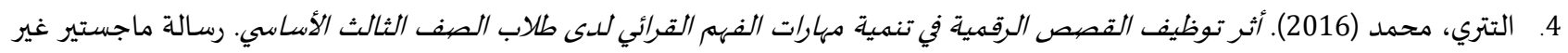
منشورة، الجامعة الأسلامية: فلسطين.

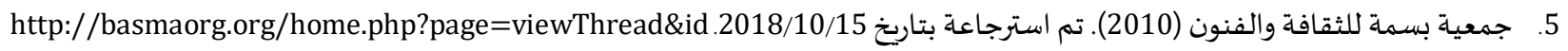

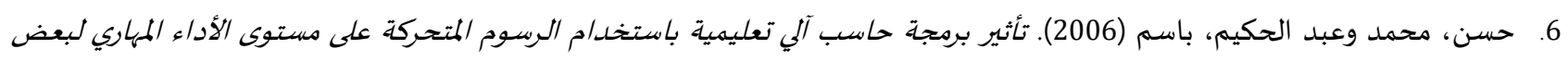

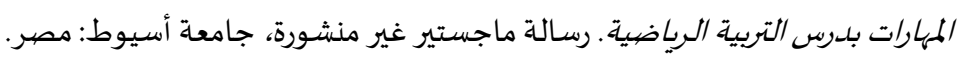

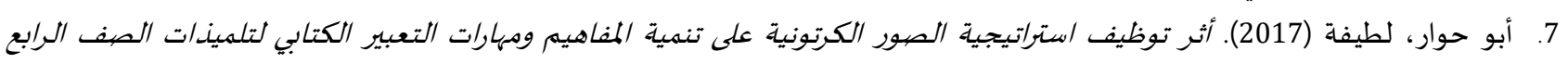

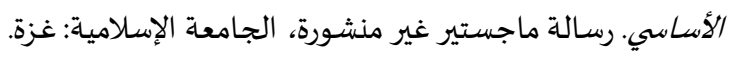


8. الحولي، عليان (2004). القيم المتضهنة في أفلام الرسوم المتحركة- دراسة تحيلية- المؤتمر التربوي الأول بعنوان "التربية في فلسطين ومتغيرات العصر" في الفترة من عانيان (2004/11/24-23. الجامعة الإسلامية: غزة.

9 9. الزق، محمد (2014). أثر توظيف الصهور المتحركة في تنمية مهارات التعبير اللغوي لدى طاب الصهف الرابع الأساسي بمحافظات غنة. رسالة ماجستير غير منشورة، جامعة الأزهر: غزة. 10. السليتي، فراس (2008). فنون اللغة المفهوم الأهمية المقلدمات البرامج التعليمية. إربد: عالم الكتب الحديثة فيثة.

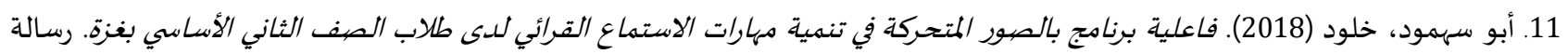
ماجستير غير منشورة، الجامعة الاسلامية: فلسطين.

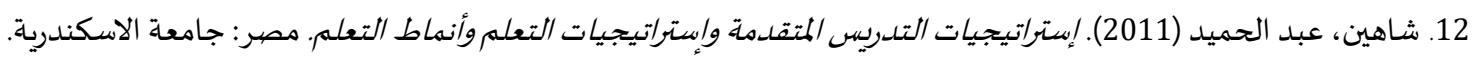

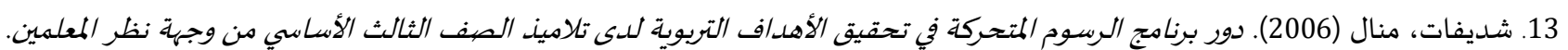
رسالة ماجستير غير منشورة، جامعة اليرموك: الأردن. 14. الشريف، أسماء (2014). أثر استخلدام الرسورم المتحركة في تعديل التصيورات البديلة للمفاهيم البيولوجية للدى طلبة الصهف التاسع الأساسي واتجاهاتهم نحوها. رسالة ماجستير غير منشورة، الجامعة الأردنية: الأردن.

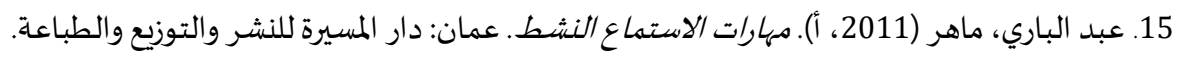
16. عبد الباري، ماهر (2011، ب). مهارات التحدث العملية والأداء. عمان: دار المسيرة للنشر والتوزيع والطباعة المانة.

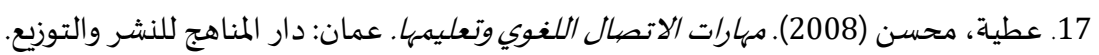
18. عون، فاضل (2012). طرائق تدريس اللغة العربية وأساليب تلدريسها. عمان: دار الصفيفاء للنشر والتوزيع. 19. العيسوي، جمال (2005). طرق تلدريس اللغة العربية بمرحلة التعليم الاساسي بين النظرية والتطبيق. دار الكتاب الجامعي.

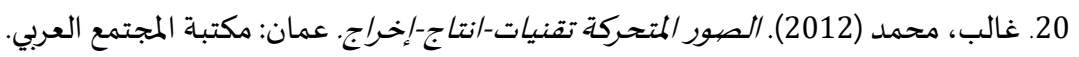

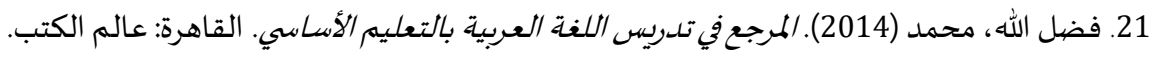

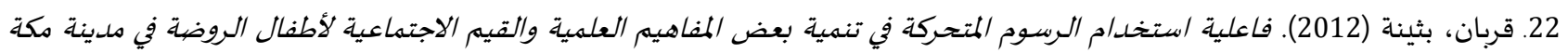

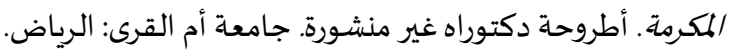

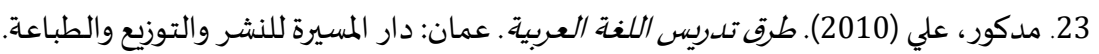

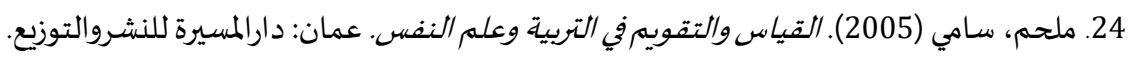

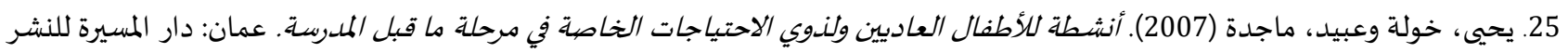
والتوزع.

ثانياً: المراجع الأجنبية:

1. Birisci, S., Metin, M., \& Karakas, M. (2010). Pre-service elementary teachers' views on concept cartoons: a sample from Turkey. Middle-East Journal of Scientific Research, 5(2): 91-97.

2. Dabell, J. (2008). Using Concept Cartoons. Mathematics Teaching Incorporating Micromath, 209, 34-36.

3. Jaenab, I., \& Athar, L. M. I. .(2014).The impact of animation movie towardas students listening skill: an experimental study at the first-year students of smkn1batulayar in academic year 2013/2014. Faculty of Language and Art Education, IKIP Mataram. From: https://journal.unnes.ac.id/sju/index.php/elt/article/view/4013

4. Kiess, Harold O. (1989). statistical concepts for the behavioral sciences. needham heights Massachusetts: allyn and bacon inc.

5. Pinter, R., Radosav, D., \& Čisar, S. M. (2012). Analyzing the impact of using interactive animations in teaching. International Journal of Computers Communications \& Control, 7(1): 147-162, https://doi.org/10.15837/ijccc.2012.1.1430.

6. Wafi, N. M. (2013). The Effectiveness of Using Animated Pictures Program in Learning English Vocabulary among the Fifth Graders in Gaza. 
المجلة الدولية للدراسـات التربوية والنفسية

International Journal of Educational \& Psychological Studies (EPS)

Journal Homepage: https://www.refaad.com/views/EPSR/Home.aspx

www.refaad.com

ISSN: 2520-4149 (Online) 2520-4130 (Print)

\title{
The effect of oriented classical arabic speaking animated images approach in the development of listening skill among second class students in Wadial-Seir district
}

\author{
Sanaa Ahmed Al-Ajrami \\ Assistant Director in Special Education \\ alajramisana@gmail.com
}

Fawaz Hassan Shehadeh

Associate Professor, University of the Middle East, Jordan

Received : 4/5/2020 Revised : 4/6/2020 Accepted : 20/7/2020 DOI : https://doi.org/10.31559/EPS2021.9.2.19

Abstract: The aim of the study is to identify the effect of animated images using the Classical Arabic language in the development listening skill for the second-class students in the Wadi Al-Seer. the study used the semiexperimantal approach the study sample was consisted of (40) students from luminous Buds school who were chosen intentionally from the private schools in Wadi Al-Seer.

They were distributed randomly for two groups; The controlled and the experimental group, Each group has(20) Students, To measure the effect of the independent variable on the dependent variable, the researcher used an achievement test it consisted of (10) multiple choice questions after applying the study materials and tools the researcher found That, there significant differences at the level $(\mathrm{a}=0.05)$ between the experimental group achievement which had been taught the listening and speaking skills by using animated images and the controlled group which had been taught in the usual method in favor of the experimental group

The study found that there are statistically significant differences between the mean scores of the total of the study in the post-application of the cognitive achievement test attributable to the method of teaching, and in favor of the experimental group that studied using the Animated Images Approach compared to the control group that was studied in the usual way, and the study recommended that school teachers should use a Animated Images Approachin teaching Arabic, and in teaching other subjects, as it has a clear impact on student achievement.

Keywords: Animated Images; listening Skill; Arabic language.

\section{References:}

1. 'bd Albary, Mahr (2011, A). Mharat Alastma' Alnsht. 'man: Dar Almsyrh Llnshr Waltwzy' Waltba'h.

2. 'bd Albary, Mahr (2011, B). Mharat Althdth Al'emlyh Walada'. 'man: Dar Almsyrh Llnshr Waltwzy' Waltba'h.

3. 'tyh, Mhsn (2008). Mharat Alatsal Allghwy Wt'lymha. 'man: Dar Almnahj Llnshr Waltwzy'.

4. 'wn, Fadl (2012). Tra'q Tdrys Allghh Al'rbyh Wasalyb Tdrysha. 'man: Dar Alsfa' Llnshr Waltwzy'.

5. Al'yswy, Jmal (2005). Trq Tdrys Allghh Al'rbyh Bmrhlh Alt'lym Alasasy Byn Alnzryh Walttbyq. Dar Alktab Aljam'y.

6. Btah, 'bd Alhlym (2016). Athr Twzyf Msrhh Aldrws Fy Tnmyt Mharat Alt'byr Alshfhy Lda Tlamyd Alsf Althalth Alasas Bghzh. Rsalt Majstyr Ghyr Mnshwrh, Aljam'h Aleslamyh: Flstyn.

7. Albtaynh, Asamh Walrshdan, Malk Walsbaylh, 'byd Walkhtatbh, 'bd (2005). S'wbat Alt'lm Alnzryh Walmmarsh. 'man: Dar Almsyrh Llnshr Waltwzy' Waltba'h.

8. Bwzan, Twny (2002). Alastkhdam Alaqsa Ltaqat Aldmagh Al'qly. T2. Trjmh (Elham Khwry). Dmshq: Dar Alhsad Lltba'h Walnshr Waltwzy'.

9. Fdl Allh, Mhmd (2014). Almrj' Fy Tdrys Allghh Al'rbyh Balt'lym Alasasy. Alqahrh: 'alm Alktb.

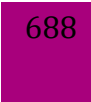

المجلة الدولية للدراسات التربوية والنفسية- المجلد9، العدد2- 2021، ص: 677-689 
10. Ghalb, Mhmd (2012). Alswr Almthrkh Tqnyat-Antaj-Ekhraj. 'man: Mktbh Almjtm' Al'rby.

11. Hsn, Mhmd W'bd Alhkym, Basm (2006). Tathyr Brmjt Hasb Aly T'lymyh Bastkhdam Alrswm Almthrkh 'la Mstwa Alada' Almhary Lb'd Almharat Bdrs Altrbyh Alryadyh. Rsalt Majstyr Ghyr Mnshwrh, Jam't Asywt: Msr.

12. Abw Hwar, Ltyfh (2017). Athr Twzyf Astratyjyh Alswr Alkrtwnyh 'la Tnmyt Almfahym Wmharat Alt'byr Alktaby Ltlmydat Alsf Alrab' Alasasy. Rsalt Majstyr Ghyr Mnshwrh, Aljam'h Aleslamyh: Ghzh.

13. Alhwly, 'lyan (2004). Alqym Almtdmnh Fy Aflam Alrswm Almthrkh- Drash Thylyh- Alm'tmr Altrbwy Alawl B'nwan "Altrbyh Fy Flstyn Wmtghyrat Al'sr" Fy Alftrh Mn23-24/11/2004. Aljam'h Aleslamyh: Ghzh.

14. Jm'yt Bsmh Llthqafh Walfnwn (2010). Tm Astrja'h Btarykh 15/10/2018. http://basmaorg.org/home.php?page=viewthread\&id

15. Mdkwr, 'ly (2010). Trq Tdrys Allghh Al'rbyh. 'man: Dar Almsyrh Llnshr Waltwzy' Waltba'h.

16. Mlhm, Samy (2005). Alqyas Waltqwym Fy Altrbyh W'lm Alnfs. 'man: Daralmsyrh Llnshrwaltwzy'.

17. Qrban, Bthynh (2012). Fa'lyt Astkhdam Alrswm Almthrkh Fy Tnmyh B'd Almfahym Al'lmyh Walqym Alajtma'yh Latfal Alrwdh Fy Mdynt Mkh Almkrmh. Atrwht Dktwrah Ghyr Mnshwrh. Jam't Am Alqra: Alryad.

18. Shahyn, 'bd Alhmyd (2011). Estratyjyat Altdrys Almtqdmh Westratyjyat Alt'lm Wanmat Alt'lm. Msr: Jam't Alaskndryh.

19. Shdyfat, Mnal (2006). Dwr Brnamj Alrswm Almthrkh Fy Thqyq Alahdaf Altrbwyh Lda Tlamyd Alsf Althalth Alasasy Mn Wjht Nzr Alm'Imyn. Rsalt Majstyr Ghyr Mnshwrh, Jam't Alyrmwk: Alardn.

20. Abw Shmwd, Khlwd (2018). Fa'lyt Brnamj Balswr Almthrkh Fy Tnmyt Mharat Alastma' Alqra'y Lda Tlab Alsf Althany Alasasy Bghzh. Rsalt Majstyr Ghyr Mnshwrh, Aljam'h Alaslamyh: Flstyn.

21. Alshryf, Asma' (2014). Athr Astkhdam Alrswm Almthrkh Fy T'dyl Altswrat Albdylh Llmfahym Albywlwjyh Lda Tlbt Alsf Altas' Alasasy Watjahathm Nhwha. Rsalt Majstyr Ghyr Mnshwrh, Aljam'h Alardnyh: Alardn.

22. Alslyty, Fras (2008). Fnwn Allghh Almfhwm Alahmyh Almqdmat Albramj Alt'lymyh. Erbd: 'alm Alktb Alhdythh.

23. Alttry, Mhmd (2016). Athr Twzyf Alqss Alrqmyh Fy Tnmyh Mharat Alfhm Alqra'y Lda Tlab Alsf Althalth Alasasy. Rsalt Majstyr Ghyr Mnshwrh, Aljam'h Alaslamyh: Flstyn.

24. Yhya, Khwlh W'byd, Majdh (2007). Anshth Llatfal Al'adyyn Wldwy Alahtyajat Alkhash Fy Mrhlt Ma Qbl Almdrsh. 'man: Dar Almsyrh Llnshr Waltwzy'.

25. Alzq, Mhmd (2014). Athr Twzyf Alswr Almthrkh Fy Tnmyt Mharat Alt'byr Allghwy Lda Tlab Alsf Alrab' Alasasy Bmhafzat Ghzh. Rsalt Majstyr Ghyr Mnshwrh, Jam't Alazhr: Ghzh. 